\title{
Performance Management Execution For Effective And Continuous Employee Appraisals
}

Barbara A. Alston, Nova Southeastern University, USA

Bahaudin G. Mujtaba, Nova Southeastern University, USA

\begin{abstract}
Most new managers tend to be fearful of assessing the performance of their employees. However, when planned in advance, performance assessment sessions need not be unpleasant or uncomfortable for the manager or the employee. There are several phases in the performance appraisal process, including planning, execution, assessment, and performance review. Based on the review of literature and personal experiences of the authors, this paper starts with a discussion of performance management programs and focuses on the performance execution aspect of a comprehensive performance appraisal system. The authors discuss what managers can and must do to successfully implement an effective appraisal system. Finally, the authors provide practical recommendations for what managers and supervisors should avoid in their employee assessment and evaluation processes.
\end{abstract}

\section{PERFORMANCE MANAGEMENT PROGRAMS}

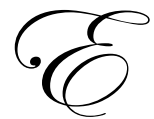

ffective leaders and managers of modern organizations know that their personal and professional success depends on their ability to qualitatively manage performance of the entire human resources in the company. As a matter-of-fact, Ashford Chea (2008) writes that "Studies have shown that highly effective people (HEP) are aware of the qualities that contribute to their success and credibility" (2008). Highly effective managers and leaders need to manage their own performance as well as the work and productivity of their employees, peers, and suppliers. Effective leadership and management begin with successful self-leadership and, due to the inevitable workplace interdependencies it must extend to one's immediate employees and peers.

Twenty-first century organizations and their leaders must understand and realize that their most important asset in achieving long-term success is not necessarily their technologies, but this competitive edge and the key to success lies in their people (Mujtaba, 2008). This is why continuous performance assessment, coaching and developing of each employee in the organization is so critical in today's competitive workplace. Performance assessment and developing people are important elements of a holistic paradigm for the growth and development of organizations through effective performance management systems. Herman Aguinis defined performance management as the "continuous process of identifying, measuring, and developing the performance of individuals and teams and aligning performance with the strategic goals of the organization" (2007). This definition emphasizes that an effective performance management program requires continuous feedback and improvement processes for the development of people. Aguinis states that "A system that involves employee evaluations once a year without an ongoing effort to provide feedback and coaching so that performance can be improved is not a true performance management system" (2007). Furthermore, a performance management program that does not explicitly make clear the employee's contribution to the goals of the organization is not a true performance management system. Aguinis highlights that a true performance management system makes the following contributions with regard to employee performance, morale and organization (as cited by Mujtaba, 2008):

1. Motivation for performance increases.

2. Self-esteem of each employee increases. 
3. Managers gain more information about their employees on a regular basis.

4. The definition of jobs and various tasks become clearer.

5. Self-insight and growth opportunities are enhanced.

6. Various administrative actions are more fair and relevant.

7. The organization's goals are clear to everyone.

8. Employees are more competent.

9. There is a better protection from lawsuits.

10. There is better and timely differentiation between good and poor performers.

11. The manager's perception of an employee's performance is communicated more clearly on a regular basis.

12. Change is facilitated more effectively.

The following characteristics are important ingredients of an ideal performance management system: strategic congruence, thoroughness, practicality, meaningfulness, specificity, identification of effective and ineffective performance, reliability, validity, acceptability and fairness, inclusiveness, openness, correctability, standardization, and ethicality (Aguinis, 2007). The successful implementation of a comprehensive performance management system can provide everyone the direction and support they need to enhance and improve their productivity and standards on a regular basis. Besides serving as important input or feeders to the organization's developmental efforts, performance management programs can also provide information for effective workforce planning and compensation projections. A comprehensive performance management program allows managers to gain relevant and timely insights into their employees' goals, desires and abilities, thereby enabling them to execute better motivational strategies and fairer evaluation methods for each person as per his or her performance. For employees, a comprehensive performance management program can clarify their jobs, the expectation of managers from them, as well as the perception of managers regarding their performance for each task and responsibility. A good comprehensive performance management program also provides relevant and timely information for those who need training, the type of training, and how they should be rewarded for meeting departmental and organizational goals. In addition, a comprehensive performance management program is an ongoing and neverending process. According to Aguinis, a good performance management process includes six related components: prerequisites, performance planning, performance execution, performance assessment, performance review, and performance renewal and re-contracting (2007).

According to James Rollo (2001), performance management is the process of continuously attracting, developing, and retaining talented employees. In his pocket guide book, entitled Performance Management, he provides supervisors, work groups, and human resource professionals with easy-to-use processes and forms for planning, supporting, counseling, mentoring, appraising, and recognizing employee performance. By reading this guide, one can learn how to effectively set measurable goals, build competencies, coach and mentor, conduct performance appraisals, and recognize accomplishments. One purpose of performance management in regard to people development is that effective coaching can build an employee's confidence and commitment while resolving performance and attitude problems on a just-in-time basis.

Challenges in performance management. The outcomes of an effective and comprehensive performance management program should be satisfied and productive employees, better bottom-line profits, and a better competitive position in the market or industry. Traditionally, performance management programs have been devalued due to the fact that most organizations viewed it as a single or "stand alone" initiative, rather than a strategic tool to enhance performance and achieve organizational productivity. Some people have viewed performance management programs as "touchy feely" initiatives that simply do not add much value to the organization, while others have seen it as being out of touch from the needs of an organization's human resource asset. Other reasons for the "devalued" view of performance management programs can be attributed to the view that it is considered as extra work to complete the required forms, its perception that it is part of some legal requirement by the human resource department, lack of proper training for understanding the process and its core elements, and the fact that often employees and managers are not included in the initial design and implementation processes.

Trends in performance management. The new trends toward a comprehensive performance management program are that it is now designed by, and for, managers and their employees (Mujtaba, 2008). Since managers and 
employees do not want to spend too much time with useless paperwork, the forms and processes are often planned as per their needs and in simple formats. The new trends in comprehensive performance management program include the fact that groups and teams are now taking the ownership of processes that are designed and agreed upon for their use. The new processes designed for comprehensive performance management programs are used not only by the managers and employees but also by others in the organization to make better decisions through the Human Resource Management Department. Another important trend in today's performance management programs is that the processes are linked to measurable results for the individual, department, and organization. In other words, managers and employees are now consumers of the results produced and created by the integrative and comprehensive performance management programs. Such data can be used by managers to effectively fulfill their responsibilities regarding the assessment and evaluation of each employee's performance.

\section{PERFORMANCE EXECUTION AND EMPLOYER-EMPLOYEE INTERACTIONS}

Performance execution contains both managerial and individual responsibilities. Managers are responsible for creating conditions that motivate the employee, eliminating performance problems, providing development opportunities, and reinforcing effective behavior. For example, it is the manager's responsibility to create a work environment where all employees can be recognized and fairly rewarded for their performance. Managers must also be aware of society's stereotypes and biases which can negatively impact some of their employees' self-esteem and performance. Research by Gibson, Harris, and Mick (2007) shows that while all respondents possessed entrepreneurial attitudes, female subjects' entrepreneurial attitude scores were weaker in the categories of achievement, personal control of outcomes, innovation, and perceived self-esteem. Managers must do what they can to help their employees have high self-esteem by consistently recognizing their work and setting performance goals. While more women are successfully climbing the ranks of entrepreneurs in the developed economies, it should also be noted that they also fail at a higher rate than their male counterparts (Gibson, Harris, and Mick, 2007). So, managers should be cognizant of the fact that women, minorities and certain employees might be facing specific barriers or challenges that are unique only to them and must eliminate these issues if they are to be a great performer toward departmental and organizational goals. Of course, the individual in the performance appraisal process is also responsible for achieving the stated objectives, soliciting feedback and coaching, open communication, collecting and sharing data as well as preparing for the actual review (Grote, 2002).

Eliminating performance problems and reinforcing effective behavior are both part of the communication process where managers provide feedback to employees regarding their performance. Feedback can be either positive recognition for a job well done such as "thanks" and other forms of appreciation, or it can be negative to identify and correct poor performance.

In a comprehensive performance management program, the frontline manager or supervisor tends to be more "hands on" and participative with employees in today's business. As such, supervisors tend to play more of a coaching role to include directing, facilitating and counseling their employees. The supervisor then, is the most likely person to be involved in and provide feedback for employee development to include evaluation and performance feedback.

A performance evaluation system, which should be an integrative part of a comprehensive performance management program, is as a process that involves continuous feedback as it relates to an employee's performance and where he or she fits within the organization, goal alignment, contributions that he or she has made, and goal setting for areas of improvement. Employees should be given objectives, clear expectations and a depiction of how they will be evaluated related to their performance. These expectations must be clear and specific with measurable goals tied to the goals of the organization (Nance-Nash, 2006). Evaluation programs that are developed with direct input from employees, supervisors and/or managers tend to be the best, most successful systems (Fiorenza, 2007).

\section{THE FEEDBACK PROCESS BETWEEN MANAGERS AND EMPLOYEES}

Peter McLaughlin (2007) declared that “...feedback conversations are essential. They force you to face reality, confront the problems that are causing your team to under-perform, and rise out of the swampland to a higher level of productivity - and a more enjoyable work environment." McLaughlin gives seven tips on how to 
make feedback effective: 1) ask permission to give feedback, 2) set a tone of energy and optimism, 3) focus on specifics, 4) show appreciation and say thank you, 5) confront non-performance, 6) remember it is a dialogue, not a monologue, and 7) encourage and energize.

Feedback can be defined as the exchange of information about the status and quality of work products. Feedback provides a roadmap to success which can be used to motivate, support, direct, correct, and regulate work efforts and outcomes to ensure managers and employees are in agreement on the standards and expectations of the work to be performed (Lee, 2006). Regular dialogue between a supervisor and an employee about work performance can have a positive impact toward improving both work performance as well as employee morale (Ritter et al., 2002).

Some employees, unfortunately, tend to view the performance appraisal process as a verdict or judgment of their performance. When managers provide feedback as an ongoing exchange of information, employees are more inclined to be participative in the evaluation process and receptive to the feedback.

Although feedback should be primarily given as close to the time of actual performance as possible, the appraisal process requires feedback must also be given at very specific intervals throughout the year. Problems tend to surface earlier and corrections are made sooner in these more frequent sessions.

Immediate feedback provides the employee informal performance information while directing future performance and/or behavior. These informal sessions allow a continuous channel of communication which is used to manage, regulate and improve employee performance.

A more formal setting, such as regularly scheduled "one on ones" (meetings between the manager and his/her employee), helps to assure consistent feedback is provided throughout the appraisal period. In addition, consistent "one on ones" help guide and improve employee performance. These sessions should promote open, twoway communication with managers soliciting feedback from the employee in an attempt to uncover potential obstacles that may be hindering performance. Managers should get in the habit of documenting one on ones, giving themselves another effective tool to review for the actual formal (or annual) performance appraisal.

Feedback can become a more effective part of the reviewing process by simply moving forward, embracing change and looking into the future. Supervisors should talk specifically about how employees need to improve rather than blaming, thus giving goals of continuous improvement for the employee to work towards.

When giving feedback it is the manager's responsibility to set up the meeting in such a way that puts the employee at ease. Also, managers should remain free from distractions and able to listen. Listening promotes calmness in the other person allowing the employee to be more receptive and open to the feedback that is being offered. Open-ended questions are helpful in maintaining the right structure for the conversation. "The true benefit of feedback comes from creating opportunities for continuous growth, learning and improvement...on both sides" (Gunn et al., 2005).

Steelman et al., (2004) found that employees are most motivated to alter or change their job performance when negative or unfavorable feedback is "from a credible source, is of high quality or is delivered in a considerate and constructive manner." Their research also suggests that recipients will be more responsive and inclined to modify their behavior when supervisors are aware of how they deliver feedback, asking themselves; was it quality feedback, and was it delivered in a considerate manner?

\section{GENERATIONAL DIFFERENCES BETWEEN EMPLOYEES}

It is also important to take generational differences into consideration throughout the appraisal process, including goal setting, motivation needs, and communication. There are four distinct generations working simultaneously in the workplace today, traditionalists (or veterans), baby-boomers, generation X, and generation $\mathrm{Y}$, each with its own values, beliefs and paradigms (Mujtaba, 2007; Crane, 2002). 
These generational differences affect the way we do business every single day. Traditionalists are dedicated and committed to the organization and want respect, stability and security. Boomers are often seen as "workaholics," they do not like to be controlled and need variety and flexibility in the workplace. Boomers value teamwork and human rights. Generation Xer's like their independence, they tend to have an entrepreneurial spirit, value learning, empowerment, and social responsibility. Generation Yer's tend to be more technologically savvy than their predecessors, and they value personal growth in their jobs and life.

Table 1 - Generational Differences in the United States (Mujtaba, 2007)

\begin{tabular}{|c|c|c|c|c|}
\hline Generation & Birth Years & Values & $\begin{array}{c}\text { Common } \\
\text { Characteristics }\end{array}$ & $\begin{array}{c}\text { Population in the } \\
\text { United States }\end{array}$ \\
\hline \hline Traditionalists & $1900-1945$ & $\begin{array}{c}\text { Respect, stability, and } \\
\text { security }\end{array}$ & $\begin{array}{c}\text { Dedicated and } \\
\text { committed }\end{array}$ & 75 million \\
\hline Baby Boomers & $1946-1964$ & $\begin{array}{c}\text { Teamwork and human } \\
\text { rights }\end{array}$ & $\begin{array}{c}\text { Workaholics, need } \\
\text { flexibility in the } \\
\text { workplace }\end{array}$ & 80 million \\
\hline Generation X & $1965-1976$ & $\begin{array}{c}\text { Learning, } \\
\text { empowerment and } \\
\text { social responsibility }\end{array}$ & $\begin{array}{c}\text { Wants to be involved, } \\
\text { needs stimulation, } \\
\text { likes to have fun }\end{array}$ & 46 million \\
\hline Generation Y & $1977-1994$ & $\begin{array}{c}\text { Diversity, dignity, } \\
\text { fairness and equality }\end{array}$ & $\begin{array}{c}\text { Technology and } \\
\text { personal growth }\end{array}$ & 70 million \\
\hline Cyberspace Gen & $1995-$ Present & Globalization & Internet & 30 million \\
\hline Total & \multicolumn{5}{|c|}{} & 300 million \\
\hline
\end{tabular}

The characteristics mentioned in Table 1 about each generation are generalities and do not necessarily apply to every person in each group; however, they will most likely apply more often to the individuals of the specified generation. In addition, some of the characteristics described for one generation may very well apply to individuals of other generations (Mujtaba, 2007).

Understanding generational differences can help managers and leaders overcome potential challenges in the workplace and create user friendly cultures that accommodate the needs of diverse workers. Teamwork and team learning must be encouraged as misunderstandings could potentially become a common workplace occurrence with the existence of four diverse generations of employees in the workplace.

\section{ELIMINATING POOR PERFORMANCE}

Proper training must be provided for each and every employee to ensure they all have the tools necessary to perform the basic functions of their job. Poor performance may lead to uncertainties about whether the employee received proper training and should be addressed immediately with additional training. It is always best to spend extra time and effort with a poor performer in an attempt to turn the performance around. If successful, this extra time and energy spent will far outweigh the costs of recruiting, rehiring, training, and retaining a new employee (Stanley, 2007).

While poor work performance could actually be the result of poor performance, it could also be one or a combination of the following: unclear expectations from the manager, a lack of the needed skills from the employee to actually perform the job, malfunctioning equipment, poor reporting, and so on.

Nonperformance or poor performance needs to be dealt with as soon as possible. Providing negative feedback to an employee months after an incident can be unclear and can send the wrong message to the employee.

Providing negative feedback only at the time of the actual annual appraisal could result in employee resigning or "quitting work without actually quitting the job," resulting in poor performance throughout the year. A better choice would be to provide corrective or negative feedback during one on ones allowing the employee time to reflect on the information given and the opportunity to make corrections going forward. 
In order to change poor performance, managers must conduct multiple coaching conversations and interventions to strategically and advantageously change employee behavior. "Improved performance occurs only through proper coaching, guidance, training and employee support" (Lee, 2006).

Employees want to receive feedback in a non-judgmental, non-threatening educational manner which fosters a productive employee / manager relationship. Employers should be sensitive to this, offering feedback in the same non-judgmental, non-threatening manner. Expressing disappointment or anger, verbally or non-verbally can be counter-productive. Managers and supervisors should be specific when addressing poor performance and be just as specific when offering praise (Anonymous, 2003).

\section{REINFORCING EFFECTIVE BEHAVIOR}

Meaningful feedback can bring to an end ineffective behaviors, it can be used to guide, encourage and reinforce competent and proficient behaviors as well as motivating employees (Steelman, 2004). Written appreciation, spoken compliments, announcing accomplishments in front of peers, letters or emails copied to senior staff, awarding time off, plaques, etc. are all examples of reinforcing effective behavior and positive feedback.

Unfortunately, some managers think that bonuses or time off are the only motivation that is required when recognizing a job well done. In fact, managers should acknowledge accomplishments more often than they acknowledge mistakes, this is more effective. Repeated positive feedback or repeated negative feedback should follow repeated appropriate or inappropriate behavior (McAndrews, 2005). According to Grote (2002), there are six techniques that can have a "predictable effect on increasing an individual's motivation" and they are presented in Table 2 .

Table 2 - Techniques for Increasing Employee Motivation (Grote, 2002)

\begin{tabular}{|ll|}
\hline - & Create opportunities for achievement and accomplishment. \\
\hline - & Allow people freedom, discretion, and autonomy in doing the job. \\
\hline - & Provide opportunities for learning and growth. \\
\hline - & Increase the amount of challenge. \\
\hline - & Make sure the work itself is inherently capable of motivation. \\
\hline
\end{tabular}

\section{HOLDING “ONE ON ONES” MEETINGS}

Managers and supervisors alike should include regularly scheduled "one on ones" into their day-to-day operations and business routine. This type of manager/employee meeting helps foster communication as well as aid in the development and strengthening of relationships within the organization. The primary focus in a "one on one" session is the employee or team member. These sessions should be scheduled, at a minimum, on a monthly basis. Be sure to include these key elements into your one on ones (meetings) to ensure a great session:

- $\quad$ Meet with your employee at regularly scheduled intervals.

- $\quad$ Meetings should be conducted in a private office or conference room.

- $\quad$ As a rule of thumb, sessions should last approximately thirty minutes.

- $\quad$ During the session, the primary focus should be on the employee, however do include some conversation about you, the manager, in addition to career growth and development conversation for the employee.

- $\quad$ Be prepared ahead of time. Include follow up questions from previous one on ones, questions related to current work or projects, etc.

- $\quad$ Be committed to following up.

- $\quad$ Be sure to include positive feedback as well as offer any necessary corrective feedback.

- $\quad$ Close with asking the employee what questions or suggestions do they have for you. 
Regularly scheduled one on ones promote opportunities to uncover methods for improvement, reinforce good behaviors, remove obstacles that may hinder performance, and support and strengthen accomplishments. And it is with advanced planning that one on ones will be more effective. Find a system that will work for you to track performance information such as a performance log or journal. Something as simple as a journal, notepad, or a computer file would be sufficient as outlined in Appendix A. Keep track of achievements and accomplishments and also document developmental opportunities.

Table 3 - Do's \& Don'ts in Performance Assessment Meetings

\begin{tabular}{|l|}
\hline Do's: \\
\hline \hline Do conduct regular one on one's \\
Do document employee performance \\
Do identify specifics \\
Do review your employees fairly \\
Do make your employees feel comfortable during the feedback session \\
Do talk specifically about what needs to improve \\
Do look forward and embrace change \\
Do agree on an action plan \\
Do remain impartial and open minded \\
\hline
\end{tabular}

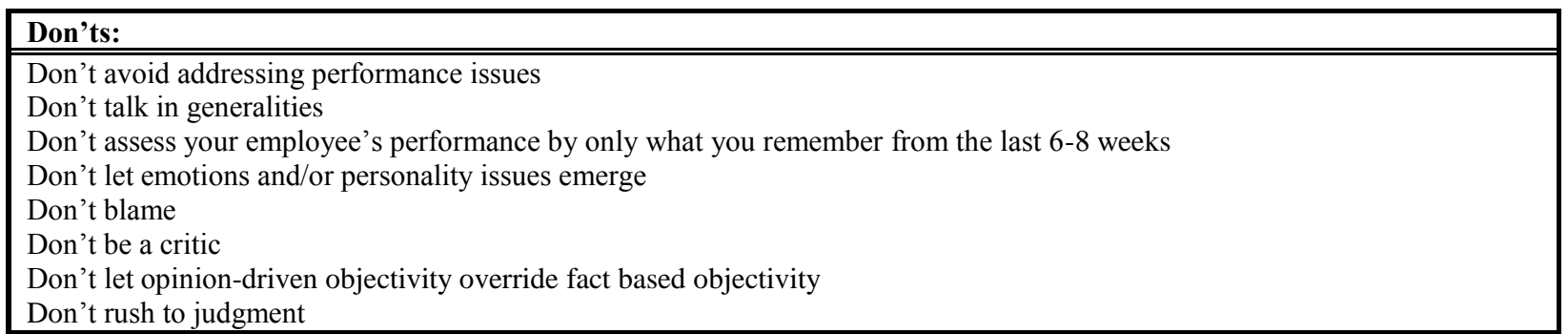

Surprisingly, supervisors can even find ways they can improve their own performance just by listening to their employees during these sessions (Ritter et al., 2002). Furthermore, supervisor and managers can create a personal list of reminders for their performance management discussions with their employees and pay attention to the common "Do's and Don'ts" of performance assessment meetings. To help guide a manager through the process, Table 3 depicts a list of Do's and Don'ts that any manager or supervisor can use in the performance execution phase of a performance appraisal process.

\section{SUMMARY}

A complete performance evaluation system is a process that involves continuous feedback as it relates to where an employee fits within the organization, goal alignment, where his/her contributions have made a difference, and where there is room for improvement. Employees should be given clear and specific expectations with measurable goals, tied to the goals of the organization (Nance-Nash, 2006).

The performance execution of a performance appraisal process contains managerial responsibilities and individual responsibilities. Managers are responsible for creating conditions that motivate the employee, eliminating performance problems, providing development opportunities, and reinforcing effective behavior. The individual in the performance appraisal process is responsible for achieving the objectives, soliciting feedback and coaching, open communication, collecting and sharing data as well as preparing for the actual review (Grote, 2002).

It is also important to take generational differences into consideration throughout the appraisal process in order to effectively interact with each employee and motivate everyone in the department according their personal likes and desires. There are several distinct generations in the workplace today, each with its own values, beliefs and paradigms that affect their work. 
Managers owe their employees an honest evaluation. It is every manager's responsibility to provide ongoing feedback and coaching to his or her direct reports. A good leader will create the conditions that are necessary to motivate employees as well as confront and eliminate performance problems as they arise. The following are strategic and practical recommendations for managers or supervisors at any level:

- Give clarity to your employees on how their performance goals contribute to the goals of the organization.

- Include your employees, supervisors and/or other managers in the evaluation process.

- $\quad$ Provide mandatory ongoing performance appraisal training for supervisors or managers on the basic concepts of the performance appraisal process to include setting goals, evaluating performance, providing constructive feedback, etc. All to ensure the success of the evaluation program.

- Continuously communicate to ensure your employees are moving in the right direction and meeting objectives. On-going dialogue allows managers the opportunity to get an employee back on track that may be moving in the wrong direction in addition to giving employees an understanding of where they are in the appraisal process.

Last but not least, do not forget to regularly and honestly appreciate and thank employees for their contributions and efforts toward the achievement of departmental and organizational goals. Employees have a right to know how they are doing in their jobs, and it is the manager's responsibility and obligation to keep them informed of their performance on a regular basis.

\section{AUTHOR INFORMATION}

Barbara Alston's graduate work includes a Doctorate in Business Administration with a concentration in Human Resources from Nova Southeastern University, as well as a Master of Business Administration and Bachelor of Business Administration from Averett University in Virginia. Barbara is currently a Branch Manager with Paychex, Inc. in Orlando, Florida. In addition, she teaches graduate and undergraduate business courses at Nova Southeastern University, College of the Southwest and the University of Phoenix. With over 18 years of management experience, she brings a wealth of business knowledge and business management skills into the classroom.

Bahaudin G. Mujtaba is Department Chair for Management as well as an Associate Professor of Management, Human Resources and International Management. In the years 2003-2005, he was the Director of Institutional Relations, Planning, and Accreditation for Nova Southeastern University at the H. Wayne Huizenga School of Business and Entrepreneurship in Fort Lauderdale, Florida. As a director, he was responsible for the planning of accreditation reviews for all Huizenga School's academic programs in all locations throughout United States of America and abroad.

\section{REFERENCES}

1. Alston, B. A. and Mujtaba, B. G. (2008). Performance Management and Execution: Strategically Providing Effective Feedback through Ongoing Appraisal Systems. Proceedings of Oxford Business and Economics Conference, ISBN: 978-0-9742114-7-3; June 22-24, 2008; Oxford, United Kingdom.

2. Aquinis, H. (2007). Performance management. Pearson Prentice Hall; Upper Saddle River, New Jersey.

3. Anonymous (2003). For better reviews, give feedback a "future spin". Accounting Office Management \& Administration Report. New York. 03(4) 1-4.

4. Chea, A. C. (Winter 2008). Self-management and personal leadership: why and how highly effective people succeed in achieving their goals in organizations. SAM Management In Practice, Vol 12(1), pages $1-8$.

5. Crane, T.G., (2002). The heart of coaching: using transformational coaching to create a high performance culture. FTA Press - San Diego, CA.

6. $\quad$ Fiorenza, Nicholas (2007). Tuning up performance. Printing Impressions. 49(8) 54.

7. Gibson, S. G; Harris, M. L.; and Mick, T. D. (2007). A glass ceiling in entrepreneurship? SAM Management In Practice, Vol 11(4), pages 1-8.

8. Grote, D. (2002). The performance appraisal question and answer book: survival guide for managers. AMACOM - New York, NY. 
9. $\quad$ Gunn, R.W., Gullickson, B.R., (2005). Feedback:gift to the giver. Strategic Finance. 87 (2) 8-10.

10. Lee, C. (2006). Feedback, not appraisal. HRMagazine. 51(11) 111-115.

11. McAndrews, J. (2005). Managers should apply positive and negative feedback. American Agent \& Broker. 77 (7) 16-18.

12. Mclaughlin, P. (2007). Giving good feedback. SuperVision. 68(2) 7.

13. Mujtaba, B. G. (2008). Coaching and Performance Management: Developing and Inspiring Leaders. ILEAD Academy Publications; Davie, Florida, USA. ISBN: 978-0-9774211-4-5.

14. Mujtaba, B. G., (2007). Mentoring diverse professionals ( $2^{\text {nd }}$ edition). ILEAD Academy, Davie, Florida.

15. Nance-Nash, S. (2006). Everybody's a critic. PM Network. (20) 1036.

16. Ritter, B., Nunnally, K. (2002) Formalize the feedback: employee performance evaluations. Rural Telecommunications. 21(3) 32-36.

17. Rollo, James (2001). Performance Management: A pocket guide for employee development. Competitive Advantage Consultants Inc. and Goal QPC Publications. Website: www. goalqpc. com; Phone: (800) 6434316.

18. Stanley, T.L. (2007). Poor performance and due process. SuperVision. 68 (1) 8.

19. Steelman, L., Rutkowski, K. (2004). Moderators of employee reactions to negative feedback. Journal of Managerial Psychology. 19 (1/2) 6.

\section{Appendix A - Note Taking or Journal Keeping Sample for "One on One's"}

Name:

Date:

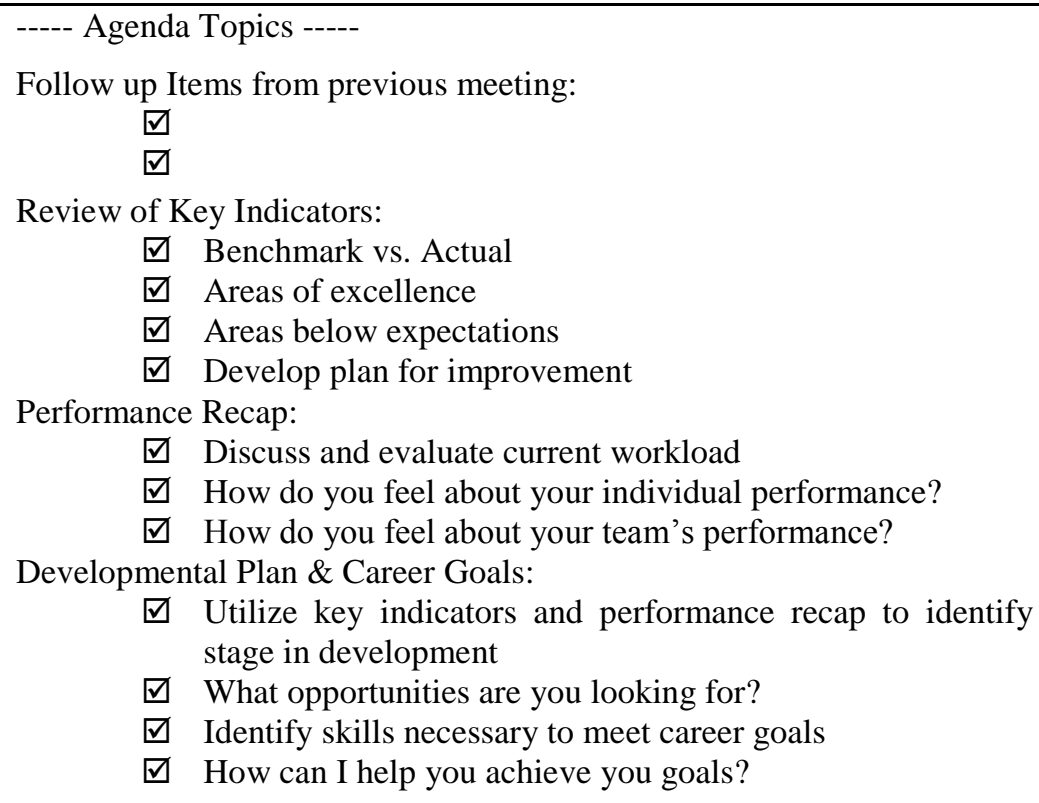

Misc. Discussion:

Action Items for next meeting:

$\square$

$\square$ 
Journal of Business \& Economics Research-September, 2009 Volume 7, Number 9 NOTES 